\title{
DESIGUALDADES EDUCACIONAIS EM METRÓPOLES: TERRITÓRIO, NÍVEL SOCIOECONÔMICO, RAÇA E GÊNERO
}

\author{
MaURicio ERNicA ${ }^{1}$ \\ Erica Castilho Rodrigues ${ }^{2}$
}

\begin{abstract}
RESUMO: Este artigo trata das desigualdades de aprendizagem entre grupos sociais em metrópoles, abordando o caso do município de São Paulo. Identificamos um padrão na cidade, segundo o qual, pela ordem, têm maior desempenho: meninas brancas, meninas pardas, meninos brancos, meninos pardos, meninas pretas e meninos pretos. Esse padrão perdura no interior dos distritos. A principal variação é que, nos distritos mais desiguais, as desvantagens raciais são fortes, afetando meninas e meninos pretos. Por sua vez, nos distritos mais equitativos, as desvantagens dos meninos pretos persistem, enquanto as meninas pretas têm maior desempenho, aproximando-se dos meninos brancos e pardos.
\end{abstract}

Palavras-chave: Educação e desigualdades. Metrópoles. Nível socioeconômico. Raça. Gênero.

\section{EDUCATIONAL INEQUALITIES IN METROPOLISES: TERRITORY, SOCIOECONOMIC STATUS, RACE, AND GENDER}

\begin{abstract}
This paper focuses on learning inequalities between social groups in metropolises. We could identify a persistent pattern throughout the city of São Paulo, according to which these groups perform better in the following order: white girls, brown girls, white boys, brown boys, black girls, and black boys. This order almost does not change within the districts. Nevertheless, there is a variation in this pattern of inequalities within the districts: within the most unequal ones, the racial disadvantages are more noticeable, affecting black girls and boys. On the other hand, in the most equitable districts, the black boys' disadvantages persist while black girls have better performance, approaching the white and brown boys.
\end{abstract}

Keywords: Education and inequalities. Metropolises. Socioeconomic status. Race. Gender.

O artigo apresenta resultados do projeto Redes de Grupos de Pesquisa em Educação e Desigualdades, apoiada pela Fundação Tide Setubal.

1.Universidade Estadual de Campinas -Faculdade de Educação - Campinas (SP), Brasil. E-mail: ernica@unicamp.br

2.Universidade Federal de Ouro Preto - Departamento de Estatística - Ouro Preto (MG), Brasil. E-mail: ericacastirodrigues@gmail.com 


\title{
DESIGUALDADES EDUCATIVAS EN METRÓPOLIS: TERRITÓRIO, CONDICIÓN SOCIOECONÓMICA, RAZA E GÉNERO
}

\begin{abstract}
RESUMEN: Este artículo aborda las desigualdades de aprendizaje entre grupos sociales en metrópolis. Identificamos un patrón persistente en toda la ciudad de São Paulo según el cual se desempeñan mejor, en orden: niñas blancas, niñas mestizas, niños blancos, niños mestizos, niñas mestizas, niñas negras y niños negros. Este sistema de posiciones casi no cambia dentro de los distritos. La principal variación es que, en los distritos más desiguales, las desventajas raciales son fuertes y afectan a las niñas y los niños negros. Sin embargo, en los distritos más equitativos, las desventajas de los niños negros persisten, mientras que las niñas blancas tienen mejor rendimiento, acercándose a los niños blancos y mestizos.
\end{abstract}

Palabras-claves: Educación y desigualdades. Metrópolis. . Condición socioeconómica. Raza. Género.

\section{Introdução}

A

s metrópoles brasileiras são cidades cujas atividades estatais e do setor empresarial exercem centralidade e influência sobre ampla rede de cidades no território nacional (IBGE, 2008). Ao todo, existem 12 metrópoles no Brasil: São Paulo, Rio de Janeiro, Belo Horizonte, Recife, Porto Alegre, Salvador, Brasília, Fortaleza, Curitiba, Goiânia, Belém e Manaus. Em 2010, os arranjos populacionais ${ }^{1}$ baseados nelas concentravam quase 63 milhões de pessoas, $1 / 3$ da população nacional. No maior deles, o de São Paulo, viviam pouco mais de 19,5 milhões de habitantes, cerca de 10\% da população do país.

Essas metrópoles são marcadas por desigualdades agudas. Concentram riquezas diversas (econômica, política, cultural, simbólica) e nutrem amplas redes de relações internacionais; ao mesmo tempo, são socialmente segregadas, possuindo vastas áreas de concentração de pobreza. No campo educacional, enquanto sediam a maioria das principais instituições de ensino superior e das escolas privadas de mais alto desempenho acadêmico do país, suas escolas públicas regulares, como padrão geral, têm desempenho inferior ao das cidades médias de seus estados (RIBEIRO; KOSLINSKI, 2009; PADILHA et al., 2012).

Os sistemas públicos de ensino dessas metrópoles têm sido objeto de uma série de pesquisas, dedicadas, sobretudo, aos casos do Rio de janeiro e de São Paulo². Para além de suas diferenças, é possível identificar pontos em comum nessa literatura quanto ao objeto das desigualdades, aos sujeitos desiguais, aos padrões assumidos por essas desigualdades e às explicações desses padrões.

No que diz respeito ao objeto da desigualdade - o quê é distribuído desigualmente -, investiga-se a distribuição desigual de oportunidades e resultados educacionais entre regiões das cidades. Os trabalhos dedicados a territórios específicos, caso dos que tratam do efeito de território/bairro, podem ser entendidos como explicações da posição da localidade na estrutura de desigualdades. Quanto aos sujeitos dessas desigualdades - quem é desigual -, são estudados, majoritariamente, grupos sociais definidos por, além do território que habitam e/ou onde estudam, sua posição social, medida normalmente por algum indicador de nível socioeconômico (NSE).

Também há convergências no que se refere aos padrões assumidos por essas desigualdades educacionais, embora variem em função das particularidades das desigualdades socioespaciais de cada cidade. Para o caso paulistano, Torres et al. (2008), Perosa et al. (2015) e Ernica e Batista (2012) descrevem dois padrões: i) as oportunidades educacionais são distribuídas desigualmente na cidade, estando as mais precárias nas 
regiões mais periféricas e/ou com alta concentração de pobreza; ii) estudantes de famílias com escolaridade e riqueza econômica semelhantes (medidas por seu NSE) têm resultados de aprendizagem diferentes conforme a localização das escolas em que estudam, tendo a variação de desempenho relação direta com a variação da riqueza da localidade de cada escola. O segundo padrão é particularmente importante, porque evidencia que, embora o NSE seja um preditor muito forte dos resultados educacionais, seu efeito é alterado - ora intensificado, ora abrandado - por outra estrutura, com lógica específica e relativa autonomia: as desigualdades socioespaciais.

Por fim, quanto às explicações desses padrões, são apontados dois processos maiores. Um é a transposição dos padrões de segregação socioespacial para o sistema escolar, no qual, transformados, assumem forma de segregação escolar. O outro é a distribuição desigual e regressiva, ao longo da cidade e dos sistemas de ensino, de recursos de políticas sociais e educacionais.

Dois mecanismos principais são apontados como produtores da segregação escolar a partir da segregação socioespacial: o papel do sistema de matrículas e o papel da estrutura de concorrência entre os agentes envolvidos no espaço educacional - as famílias, as unidades escolares e os docentes (ERNICA; BATISTA, 2012; ERNICA, 2013; ALVES et al., 2015a; ALVES et al., 2015b; COSTA; KOSLINSKI, 2011; 2012; KOSLISNKI; ALVES, 2012).

Os trabalhos que abordam a alocação de recursos de políticas sociais e educacionais enfatizam, de modo mais geral, a oferta precária de serviços públicos responsáveis por direitos sociais nas regiões de concentração de pobreza, isolando e sobrecarregando essas escolas - que também concentram os estudantes mais pobres e mais distantes da lógica escolar - com demandas que elas não têm condições adequadas de abordar (ERNICA; BATISTA, 2012). De modo mais específico, esses trabalhos abordam a distribuição desigual e regressiva de oportunidades educacionais (ERNICA; BATISTA, 2011; ERNICA, 2013; KOSLINSKI et al. 2013; PEROSA et al., 2015; TORRES et al., 2008).

O presente artigo se inscreve nessa literatura, mas procura desenvolver dois aspectos que não têm sido suficientemente explorados por ela. Em primeiro lugar, pretende descrever o padrão das desigualdades educacionais entre grupos de estudantes definidos pela intersecção do NSE com dois outros marcadores sociais pouco abordados nesse debate: raça e gênero. Em segundo lugar, este artigo pretende descrever, ao mesmo tempo, a variação desse padrão de desigualdades tanto entre as regiões quanto no interior delas.

De posse dessas descrições, é possível discutir o alcance das explicações disponíveis para as desigualdades educacionais nas metrópoles. Neste trabalho, entretanto, não pretendemos formular novas explicações. O ponto máximo a que chegaremos será a discussão de uma premissa importante para essas explicações: muito embora a posição social das famílias, medida usualmente por seu NSE, seja forte preditor dos resultados educacionais de seus filhos, há outras estruturas de classificação e dominação que possuem lógicas específicas e se relacionam com a estrutura de posições sociais, produzindo desigualdades específicas entre os membros de um mesmo grupo de NSE, conforme seu gênero, sua raça e o local onde estuda.

Tanto na literatura nacional quanto na internacional, essas estruturas raramente são estudadas conjuntamente. Por consequência, se há informações sobre como cada uma delas opera, não temos um entendimento satisfatório de como suas inter-relações produzem desigualdades educacionais e, menos ainda, sobre como uma dada estrutura atenua ou intensifica o efeito das demais.

No Brasil, como vimos, embora a sociologia das desigualdades educacionais tenha se aproximado da sociologia urbana, pouco se incorporou da literatura sobre desigualdades educacionais por gênero e raça. Tampouco a sociologia urbana que estudou a segregação residencial de grupos raciais se aprofundou no problema das desigualdades educacionais (FRANÇA, 2017; TORRES, 2004). Por sua vez, há importantes trabalhos brasileiros sobre desigualdades educacionais entre grupos de raça e gênero, os quais ora estão apoiados em grandes dados estatísticos (HASENBALG; SILVA, 1990; SOARES; ALVES, 2003; ALVES et al., 2016), ora se concentram em processos intraescolares (CARVALHO, 2004, 2005; CARVALHO et al., 2014). Contudo, pouco abordam as estruturas socioespaciais. 
$\mathrm{Na}$ literatura sociológica francesa, a principal categoria analítica para explicar as desigualdades educacionais tem sido a classe social. Embora seja profícuo o encontro de sua sociologia da educação com a sociologia urbana, os trabalhos resultantes pouco incorporaram a discussão sobre gênero e raça (VAN ZANTEN, 2001; BEN AYED, 2009; 2015). Há um debate importante sobre desigualdades educacionais por gênero, por exemplo, no que se refere às diferenças de acesso, conclusão de etapas e de aprendizagens, além dos objetivos da escolarização (BAUDELOT; ESTABLET, 1992; MERLE, 2017; DE SAINT-MARTIN, 1999). Esses trabalhos mobilizam também a categoria classe social, evidenciando que o sistema de gênero se relaciona com o de classe, mas possui relativa autonomia, gerando consequências específicas. Entretanto, pouco se encontram com a sociologia que estuda desigualdades educacionais no espaço urbano. A discussão sobre raça, por sua vez, é quase inexistente na sociologia francesa sobre desigualdades, em larga medida porque o antirracismo francês do pós-guerra assumiu a forma de antirracialismo, recusando não só o emprego de raça como categoria analítica como também a produção de estatísticas oficiais sobre raça (SCHAUB, 2015).

A literatura norte-americana constituiu-se de modo diferente. Antes de tudo, a segregação racialéum tema da sociologia urbana norte-americana desde sempre, que continua a ser abordado (WILSON, 1993; WACQUANT,2001). A discussão sobre desigualdades educacionais no espaço urbano se construiu, desdeo início, em diálogo com odebate sobre a segregação racial(BECKER, 1952; VANZANTEN, 1991). Em 1954, nojulgamentodocaso Brown vs BoardofEducation, a Suprema Corte considerou inconstitucional a segregação racial nas escolas. Desde então, formuladores de políticas públicas e pesquisadores vêm se dedicando a essa questão, com frequência abordando a relação entre as estruturas racial e socioeconômica (REARDON; OWENS, 2014). Nãoà toa, então, é na literatura norte-americana que se desenvolvem trabalhos recentes sobre a interseção de raça e posição social e as segregações residencial e escolar (REARDON et al., 2019). Essa literatura debate se, e em que grau, a relação entre a estrutura de classes e as desigualdades educacionais é alterada por outras estruturas, como a racial e a socioespacial. As desigualdades educacionais entre grupos de gênero são também abordadas (REARDON et al., 2018), mas sem aprofundar a análise da relação entre a estrutura de gênero e as demais.

\section{A Construção da Pesquisa}

O objetivo deste trabalho é analisar, entre e no interior dos distritos da capital, desigualdades de aprendizagem entre grupos de estudantes definidos por três atributos sociais: NSE, raça e gênero. Analisamos os resultados para o $5^{\circ}$ ano $^{3}$.

A metodologia adota uma adaptação da que foi proposta e desenvolvida por Soares et al. (2019), para calcular nível de aprendizagem e desigualdades de aprendizagem em todos os municípios brasileiros. Usa informações da Prova Brasil, agregando resultados de 2007 a 20154. Os cálculos são feitos empregando-se a divergência de Kulbach-Leibler ${ }^{5}$, medida estatística que permite a comparação de distribuições de desempenho em provas padronizadas de grupos de estudantes. Os resultados desses cálculos permitem afirmar se a pertença a um dado grupo modifica a chance de o conjunto dos indivíduos a ele pertencentes aprender mais ou menos ${ }^{6}$.

Nossas análises foram feitas em dois momentos. Inicialmente, calculamos para cada um dos distritos dois conjuntos de indicadores: um dedicado ao nível das aprendizagens e outro dedicado a suas desigualdades internas. O primeiro conjunto de indicadores mede o nível de aprendizagem do conjunto dos estudantes do distrito observado, que é definido pela distância entre a distribuição da aprendizagem observada desses estudantes e uma distribuição assumida como referência. Tal distribuição de referência foi calculada projetando-se na escala da Prova Brasil a mudança que deveria acontecer para que os estudantes brasileiros obtivessem desempenho no Programme for International Student Assessment (PISA) equivalente ao de um país típico da Organização para a Cooperação e 
Desenvolvimento Econômico (OCDE) ${ }^{7}$ (SOARES; DELGADO, 2016). O segundo conjunto de indicadores mede as desigualdades de aprendizagem no interior dos distritos, definidas pelas distâncias entre as distribuições de aprendizagem de grupos de estudantes, por sua vez definidos por atributos sociais escolhidos: NSE, raça e gênero. Com esses indicadores, os distritos foram reunidos em quatro agrupamentos, descritos com dados sociodemográficos.

Em seguida, analisamos conjuntos de estudantes definidos pela combinação de NSE, raça e gênero. Primeiro, calculamos o nível de aprendizagem de cada grupo de estudantes na cidade. Depois, calculamos o nível de aprendizagem desses grupos em cada um dos quatro agrupamentos de distritos.

O NSE sintetiza informações sobre riqueza econômica e escolarização das famílias8. Para o cálculo do indicador de desigualdades por NSE, foram comparadas as distribuições de desempenho na Prova Brasil dos estudantes dos grupos de menor e maior NSE. A fim de construir o indicador de desigualdade por raça, foi usada a autoclassificação dos alunos no questionário socioeconômico da Prova Brasil. O cálculo do indicador de desigualdades por raça foi feito comparando-se as distribuições de desempenho na Prova Brasil dos estudantes pretos e brancos ${ }^{9}$. Quanto ao cálculo do indicador de desigualdade por gênero, foram usadas as distribuições de desempenho dos autoclassificados homens e mulheres no questionário socioeconômico do Prova Brasil ${ }^{10}$.

\section{Aprendizagens e Desigualdades entre Distritos}

Há duas constatações relativas aos indicadores de nível de aprendizagem e das desigualdades educacionais nos distritos. Os gráficos apresentados nas Figs. 1, 2 e 3 apresentam, para cada distrito da São Paulo, dois valores, obtidos pela divergência de Kulbach-Leibler (cf. nota 5). No eixo vertical, está representado o nível de aprendizagem do conjunto de seus estudantes (em Língua Portuguesa ou em Matemática); quando os valores do eixo vertical forem negativos, então a distribuição das proficiências dos estudantes do distrito observado tem valores abaixo da distribuição assumida como referência. No eixo horizontal, estão representadas as desigualdades de aprendizagem na disciplina em questão entre grupos de estudantes do distrito observado; quando os valores são negativos para os grupos por NSE, então a distribuição das proficiências dos estudantes de menor NSE do distrito tem valores inferiores ao da distribuição dos estudantes de NSE maior; quando os valores são negativos para raça, então a distribuição das proficiências dos estudantes autoclassificados pretos do distrito têm valores inferiores ao da distribuição dos estudantes autoclassificados brancos; quando os valores são negativos para gênero, a distribuição das proficiências das meninas do distrito têm valores inferiores ao dos meninos, e vice-versa.

A primeira é que, no que diz respeito à relação entre o nível de aprendizagem, seja com as desigualdades associadas ao NSE, seja com as desigualdades associadas à raça, quando os distritos têm nível de aprendizagem mais baixo, mais comumente, também apresentam desigualdades educacionais mais baixas e menor propensão à variação nos padrões de desigualdade. Por sua vez, quando os distritos têm nível de aprendizagem mais alto, apresentam maior propensão à variação nos seus padrões de desigualdade educacional por NSE e raça, havendo muito poucos distritos com desigualdade baixa e alguns distritos com desigualdade alta, inclusive alguns outliers com desigualdade muito alta.

A segunda constatação diz respeito à relação entre o nível de aprendizagem e as desigualdades associadas a gênero. Concluímos, em primeiro lugar, que, qualquer que seja o nível da aprendizagem dos estudantes do distrito, eles têm baixa propensão a se diferenciar quanto à desigualdade educacional associada a gênero. Em segundo lugar, concluímos que essa desigualdade tem valores inferiores às outras, associadas a NSE e raça. Em terceiro lugar, identificamos uma variação nos padrões das desigualdades por gênero, conforme se observa as disciplinas: as meninas têm, quase sempre, vantagens sobre os meninos em Língua Portuguesa mas não em Matemática; nessa disciplina, as desigualdades são ainda menores, sendo que, em metade dos distritos, os meninos têm vantagem e, em outra metade, as meninas. 


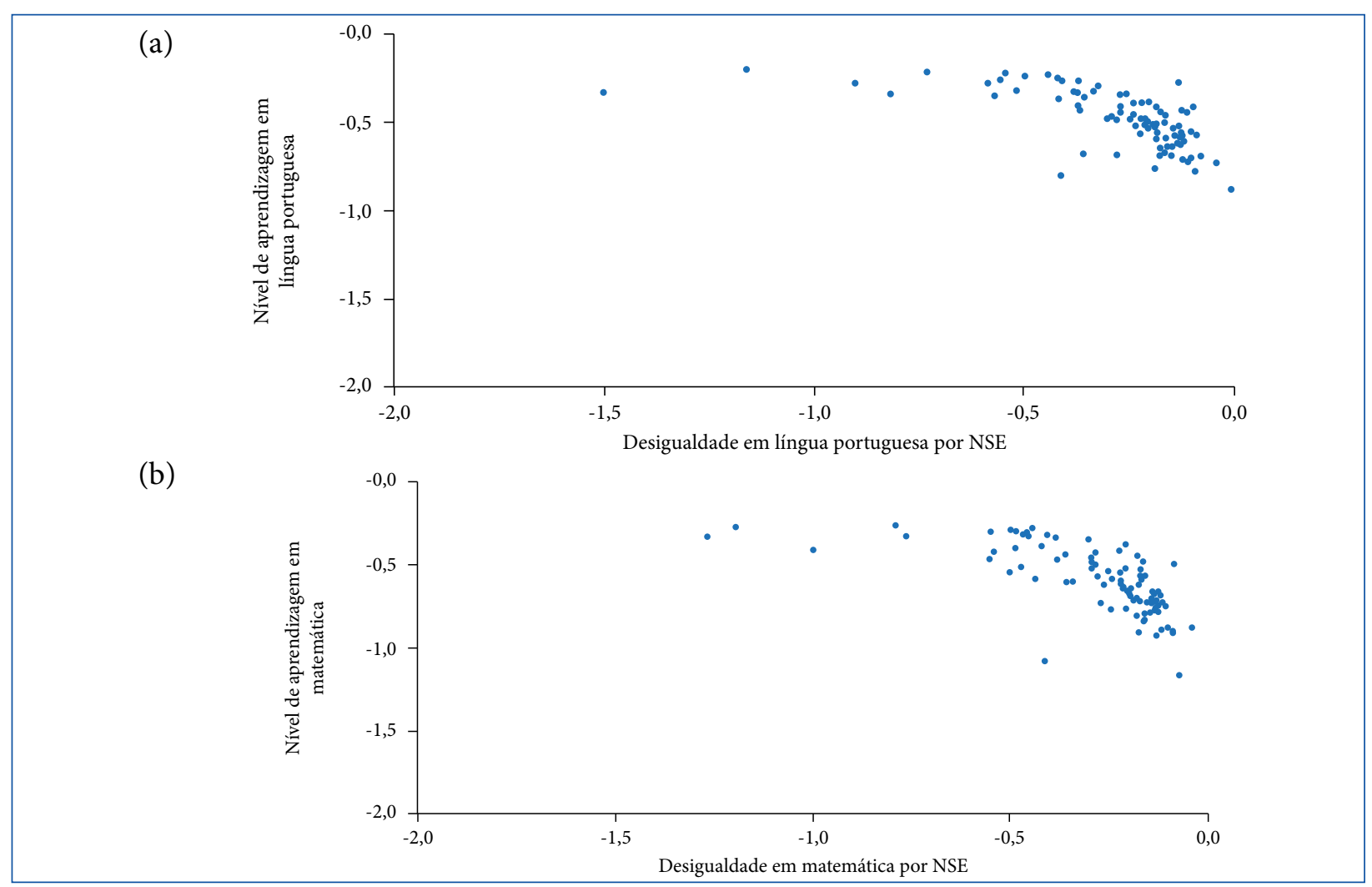

Figura 1: Nível de aprendizagem no 50 ano e desigualdade de aprendizagem entre grupos por NSE nos distritos da cidade de São Paulo. (a) em Língua Portuguesa, (b) Matemática.

(a)

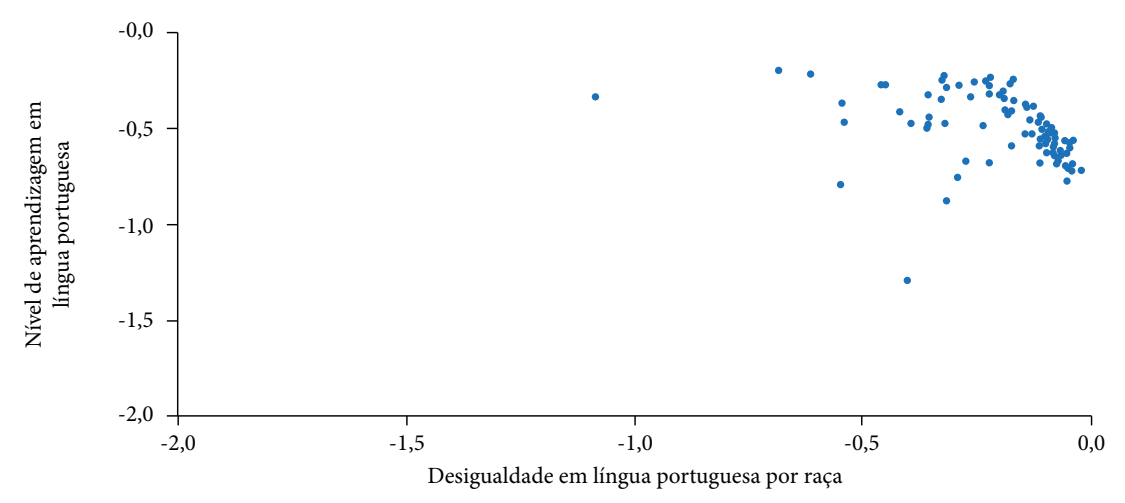

(b)

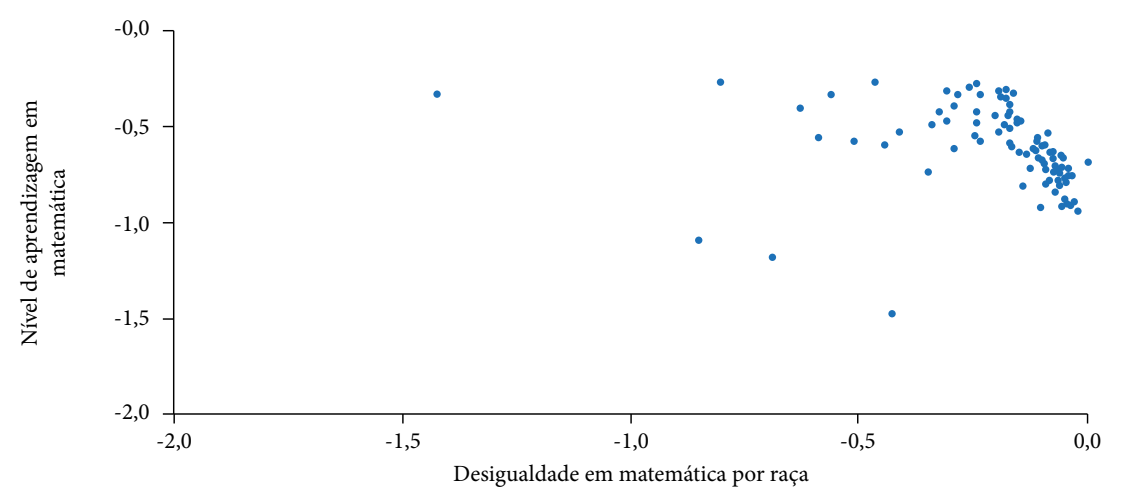

Figura 2: Nível de aprendizagem no 50 ano e desigualdade de aprendizagem entre grupos por raça nos distritos da cidade de São Paulo. (a) Língua Portuguesa, (b) Matemática. 
(a)

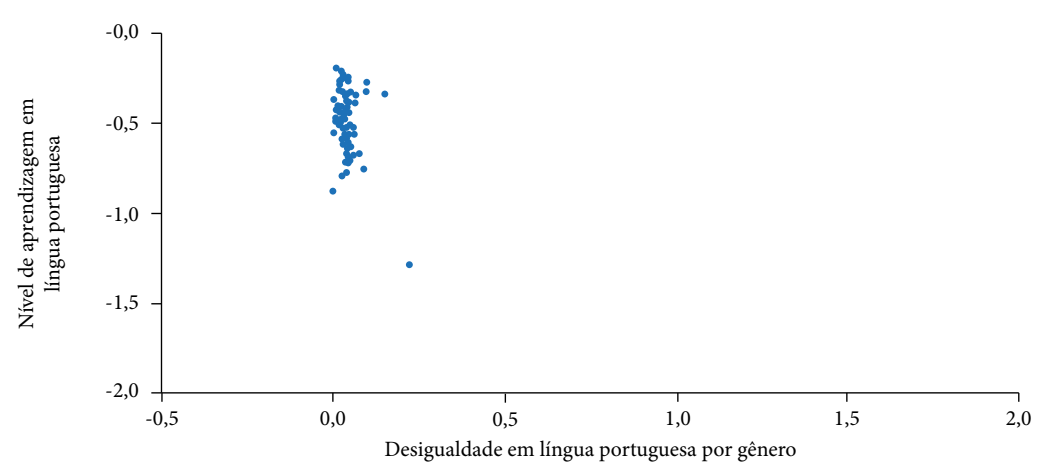

(b)



Figura 3: Nível de aprendizagem no 5o ano e desigualdade de aprendizagem entre grupos por gênero nos distritos da cidade de São Paulo. (a) Língua Portuguesa, (b) Matemática.

\section{Aprendizagem e Desigualdade entre Grupos de Estudantes}

\section{Agrupamentos de Distritos por Resultados Educacionais}

Os 95 distritos analisados foram reunidos em quatro agrupamentos, definidos estritamente pelos indicadores educacionais de nível de aprendizagem e de desigualdades por NSE e raça, calculados tanto para Língua Portuguesa quanto para Matemática.

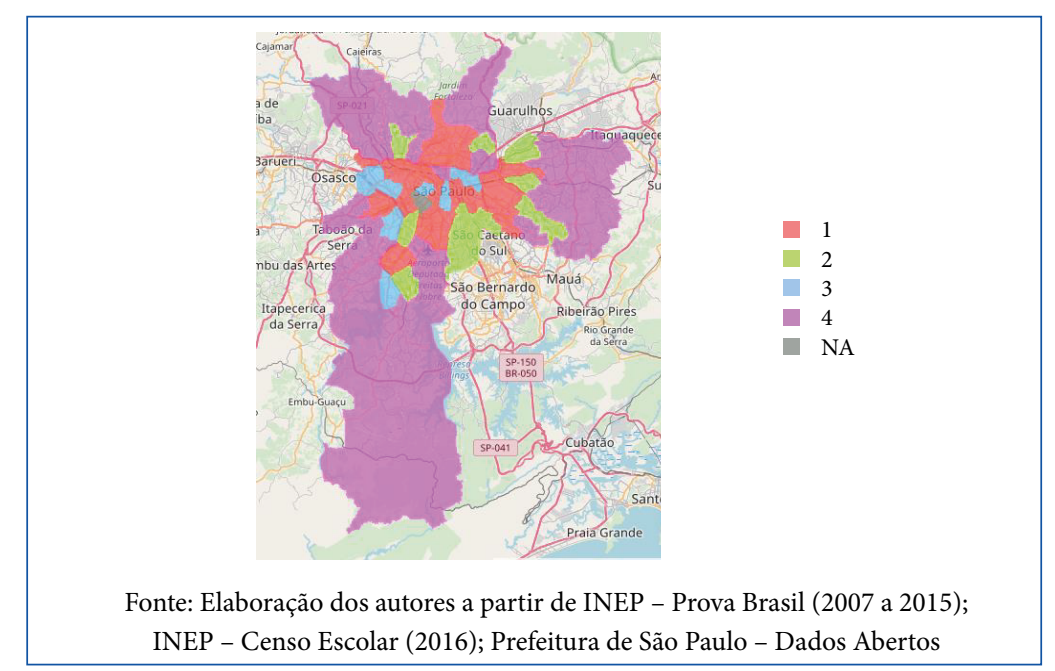

Figura 4: Mapa dos agrupamentos de distritos de São Paulo em função do nível da aprendizagem dos seus estudantes na Prova Brasil (anos iniciais) e dos seus padrões de desigualdades educacionais. 
Como essas seis variáveis são altamente correlacionadas, por meio de análise fatorial, foi possível resumir sua informação em dois indicadores. O primeiro combina as duas medidas de nível de aprendizagem. O segundo, as quatro medidas de desigualdade. Em seguida, os distritos foram posicionados em relação aos eixos definidos por esses novos indicadores. A divisão de cada eixo em dois, definindo as áreas de aprendizagens mais altas e mais baixas e as de desigualdades mais altas e mais baixas, foi feita por análise de clusters. Desse modo, chegamos a quatro agrupamentos de distritos.

\section{Agrupamento 1: Aprendizagens Maiores e Desigualdades Maiores}

Este agrupamento é o segundo maior em quantidade de distritos, reunindo 27 deles $^{11}$, nos quais habitam $20 \%$ da população paulistana. Predominam nele distritos do centro expandido da cidade, muito embora aí também estejam algumas áreas de periferia consolidada e centralidades regionais ao Norte, ao Sul, ao Leste e ao Oeste da cidade.

Esse agrupamento concentra a população mais rica da cidade de São Paulo e quase não há nele setores censitários pobres. Por um lado, $91 \%$ dos habitantes desses distritos vivem em setores censitários com os menores níveis de vulnerabilidade social ${ }^{12}$ (IPVS 1 e 2), sendo que, no conjunto da cidade, $52 \%$ da população residem em setores com essas características. Por isso, enquanto o agrupamento concentra apenas $20 \%$ da população total da cidade, ele reúne $56 \%$ de toda a população paulistana que habita em setores com IPVS 1. Por outro lado, apenas $1 \%$ de sua população habita setores com os níveis mais altos de vulnerabilidade (IPVS 5 e 6), sendo que 16\% da população da cidade vivem em setores com essas características.

No que diz respeito às matrículas no Ensino Fundamental I, no interior do agrupamento 1, 55\% delas estão concentradas no setor privado e $45 \%$ no público. Assim, se o agrupamento é responsável por apenas $16 \%$ do total das matrículas do Ensino Fundamental I da cidade, ele, no entanto, concentra quase 1/3 das matrículas da cidade no Ensino Fundamental I em escolas privadas e apenas 10\% das matrículas nesse segmento em escolas públicas.

Também os alunos das escolas públicas desse agrupamento têm posição social mais alta do que os dos demais agrupamentos. O NSE médio de todos os estudantes desse agrupamento matriculados no Ensino Fundamental I na rede pública é o maior de todos: $0,48^{13}$. Esse agrupamento também é o que possui o maior percentual de brancos entre os estudantes do Ensino Fundamental I público (47\%, contra 38\% no conjunto da cidade) e o menor percentual de pardos e pretos (39\% e $9 \%$ contra, respectivamente, $45 \%$ e $11 \%$ no conjunto da cidade).

Ou seja, o agrupamento 1 , em relação à cidade, diferencia-se por concentrar moradores ricos e também por ter alunos da rede pública mais ricos, em média, e mais brancos; dentro dele, além da desigualdade de aprendizagem marcada entre os setores educacionais privado e público (a qual não temos como medir), ${ }^{14}$ há também alta desigualdade no interior do sistema público.

\section{Agrupamento 2: Aprendizagens Maiores e Desigualdades Menores}

Este agrupamento é composto por 12 distritos $^{15}$, nos quais habitam pouco mais de $14 \%$ da população municipal. Nele, predominam distritos em áreas de periferia consolidada e centros regionais situados entre o centro expandido e os extremos periféricos; como exceção, há nele apenas um distrito da área rica e central da cidade: o Itaim Bibi.

Pode-se dizer que, nesse agrupamento, predominam os grupos sociais médios e médio-altos da cidade. Nele, o percentual da população residente em setores com IPVS 1 é ligeiramente menor que o 
da cidade: em torno de $11 \%$ no agrupamento e de $13 \%$ na cidade. A maioria (60\%) da população desse agrupamento vive em setores de IPVS 2, proporção maior do que a verificada na cidade (40\%). Muito embora seja o segundo agrupamento com o maior percentual da população habitando setores com vulnerabilidade alta (IPVS 5 e 6), com 6\%, esse percentual é menor que o encontrado na cidade (16\%).

Quanto às matrículas no Ensino Fundamental I no interior do agrupamento 2, 2/3 delas estão no setor público e $1 / 3$ no setor privado. O agrupamento reúne quase $13 \%$ do total das matrículas no Ensino Fundamental I da cidade e, no entanto, concentra $15 \%$ das matrículas do setor privado e $12 \%$ das matrículas do setor público.

O NSE médio dos alunos de suas escolas públicas expressa a posição média desse agrupamento. Seu valor $(0,37)$ é menor que o do agrupamento 1 , o mais rico, $(0,48)$ e maior do que os dos agrupamentos 3 e 4 ( 0,23 e 0,22 , respectivamente). Nesse agrupamento, há o segundo maior percentual de brancos entre os estudantes do Ensino Fundamental I público ( $43 \%$ contra 38\% no conjunto da cidade) e o segundo menor percentual de pardos e pretos ( $43 \%$ e $10 \%$ contra, respectivamente, $45 \%$ e $11 \%$ no conjunto da cidade).

\section{Agrupamento 3: Aprendizagens Menores e Desigualdades Maiores}

Este é o menor dos quatro agrupamentos, com apenas 10 distritos $^{16}$, nos quais vivem apenas $4 \%$ da população paulistana. Tanto a distribuição geográfica quanto a estrutura socioeconômica desses distritos são heterogêneas. Há distritos do centro expandido e alguns distritos em áreas de transição entre o centro expandido e os extremos periféricos da cidade.

Aqui, há expressiva concentração da população que habita setores censitários mais ricos, mas, diferentemente do agrupamento 1, no agrupamento 3, os contrastes sociais são mais acentuados. Por exemplo, dois de seus distritos (Morumbi e Socorro) são vizinhos das duas maiores favelas da cidade (Paraisópolis e Heliópolis, respectivamente). Internamente, temos que, por um lado, $50 \%$ da população do agrupamento vive em áreas ricas, com IPVS 1, valor muito acima do da cidade, que é de $13 \%$. Por outro lado, o percentual da população vivendo em setores censitários com IPVS 6, mais pobres, é de 5,5\%, valor ligeiramente menor que o da cidade $(7,5 \%)$.

As matrículas no interior do Ensino Fundamental I, no agrupamento 3, estão fortemente concentradas no setor privado, que reúne $62 \%$ delas contra $38 \%$ no setor público. Essa é a maior concentração de matrículas no setor privado entre os agrupamentos. Assim, se o agrupamento concentra 3,5\% das matrículas totais do município no Fundamental I, ele concentra apenas $2 \%$ das matrículas no setor público e $8 \%$ das matrículas no setor privado, nessa etapa. O efeito dos contrastes sociais e da forte concentração de matrículas no setor privado se vê no NSE médio dos alunos do Ensino Fundamental I das escolas públicas, que é baixo e quase igual ao do agrupamento 4, o mais pobre (0,23 no agrupamento 3 e 0,22 no agrupamento 4).

Racialmente, os estudantes do Ensino Fundamental I público desses distritos são quase idênticos aos do agrupamento 2: $41 \%$ dos estudantes são brancos contra $38 \%$ no conjunto da cidade; $43 \%$ são pardos e $9 \%$ são pretos contra, respectivamente, $45 \%$ e $11 \%$ no conjunto da cidade.

Portanto, se o agrupamento 3 se assemelha ao 4 no que diz respeito ao baixo NSE dos seus estudantes e aos padrões de baixa qualidade, assemelha-se ao agrupamento 1 no que diz respeito às altas desigualdades educacionais. Há uma diferença importante entre o perfil socioeconômico dos estudantes da rede pública dos dois agrupamentos que mais concentram a população mais rica da cidade, o 1 e o 3. No agrupamento 1, os alunos da rede pública, em média, têm o maior NSE da cidade, enquanto no agrupamento 3 o NSE é um dos mais baixos. Também há diferença entre os agrupamentos 3 e 4: enquanto o perfil socioeconômico mais baixo dos alunos do agrupamento 4 é produzido sobretudo porque nele se concentra a população mais pobre 
da cidade - resultado dos padrões de segregação atuantes ao nível da cidade -, no agrupamento 3, o baixo NSE dos discentes é produzido a partir de mecanismos de segregação que atuam no interior do próprio agrupamento, a começar pela segregação entre os setores público e privado.

Ou seja, o agrupamento 3, socialmente mais contrastado, possui mecanismos internos de desigualdade que atuam, primeiro, na segregação entre setores público e privado (que não podemos medir) e, depois, no interior do sistema público, que é um dos mais desiguais da cidade.

\section{Agrupamento 4: Aprendizagens Menores e Desigualdades Maiores}

Esse é o maior agrupamento, com 46 distritos ${ }^{17}$, concentrando $63 \%$ da população paulistana. Os distritos desse agrupamento estão concentrados nos extremos periféricos da cidade, ao Noroeste e Nordeste, ao Sul, ao Sudoeste e ao Leste, com uma exceção na região central da cidade (Bom Retiro).

Aqui está segregada a população que vive em maior situação de pobreza na cidade. A concentração é tão grande que, nesse agrupamento, vivem $92 \%$ da população da cidade residente em setores com IPVS 5 e 6. Por outro lado, a população residente em setores mais ricos (IPVS 1 e 2) nesse agrupamento é menor do que a verificada na cidade.

O agrupamento 4 também concentra as matrículas na rede pública na cidade. O agrupamento 4 concentra $67,5 \%$ das matrículas totais no Ensino Fundamental I no município, mas 45\% das matrículas municipais do setor privado e $76 \%$ das matrículas municipais no setor público. Essa grande diferença entre os percentuais das matrículas entre os setores acontece porque esse é o agrupamento com a maior concentração de matrículas no setor público (82\%).

Como efeito da concentração populacional em situação de alta vulnerabilidade social, o NSE médio dos matriculados no Ensino Fundamental I público nesse agrupamento é o mais baixo $(0,22)$. Nesse agrupamento, há o menor percentual de brancos entre os estudantes do Ensino Fundamental I público ( $36 \%$ contra $38 \%$ no conjunto da cidade) e o maior percentual de pardos e pretos $(47 \%$ e $12 \%$ contra, respectivamente, $45 \%$ e $11 \%$ no conjunto da cidade).

Em síntese, o agrupamento 4 se diferencia da cidade pela segregação da população mais pobre, o que se expressa também na concentração de matrículas na rede pública e em alunos nessa rede mais pobres. Também é o agrupamento com a maior concentração de estudantes negros.

\section{Intersecções: Território, NSE, Raça e Gênero}

Em seguida, analisamos as desigualdades de aprendizagem em Língua Portuguesa no $5^{\circ}$ ano entre grupos de estudantes formados pela combinação de NSE, raça e gênero. Para simplificar a análise, trabalhamos apenas com três categorias raciais (brancos, pardos e pretos). A análise foi feita em duas etapas: na primeira, analisamos o conjunto da cidade, para identificarmos o seu padrão geral de desigualdades; na segunda, abordamos a variação desse padrão nos agrupamentos de distritos.

Calculamos, para cada grupo social, o seu nível de aprendizagem; isto é, a distância da aprendizagem do grupo em relação à distribuição de referência. Os resultados estão apresentados na Fig. 6. No eixo vertical, estão representados os níveis de aprendizagem. As três propriedades sociais utilizadas para construir os grupos estão representadas assim: o NSE está indicado no eixo horizontal, em sentido crescente; o gênero está marcado por símbolos (triângulos para meninos e círculos para meninas); e a raça, pela cor do símbolo.

Destacamos dois resultados. O primeiro é que as propriedades sociais observadas (NSE, raça e gênero) possuem lógicas específicas, relativamente autônomas, de produção de desigualdades, as quais confirmam padrões conhecidos (ALVES et al., 2016). No gráfico, podemos observar que todos os grupos 
formados por raça e gênero têm nível de aprendizagem em Língua Portuguesa mais alto conforme aumenta o seu NSE. Além disso, as posições relativas entre os grupos formados por raça e gênero se mantêm ao longo das faixas de NSE; isto é, em cada uma das faixas de NSE, dentro de um mesmo grupo racial, as meninas estão sempre em vantagem sobre meninos e, por sua vez, em cada uma das faixas de NSE, dentro de um mesmo grupo de gênero, pessoas brancas estão em vantagem sobre as pardas, que estão em vantagem sobre as pretas.

O segundo resultado é o padrão assumido por essas desigualdades, quando se considera a intersecção dessas propriedades. Observamos que há uma regularidade ao longo das faixas de NSE: as meninas brancas têm a maior aprendizagem, seguidas das meninas pardas; em seguida, estão os meninos brancos e depois, com valores próximos e, por vezes, alternando posições, as meninas pretas e os meninos pardos; por fim, com proficiência nitidamente inferior a todos os outros grupos, estão os meninos pretos.

Devido ao efeito do NSE, que, conforme aumenta, eleva os valores da proficiência de todos esses grupos, mas não altera a ordem entre eles, podemos observar que, ao longo das faixas de NSE, a proficiência de cada grupo está disposta na forma de uma linha ascendente. Observando essas linhas, pode-se identificar que elas se dispõem em três feixes. O primeiro é formado pelos grupos que estão em posição de vantagem sobre todos os demais e têm resultados parecidos: as meninas brancas e as meninas pardas, sendo que as brancas estão em vantagem sobre as pardas. Abaixo dessas meninas, em posição intermediária, há um segundo feixe de linhas que reúne os meninos brancos, as meninas pretas e os meninos pardos; no interior dele, os meninos brancos estão em posição de vantagem sobre as meninas pretas e os meninos pardos, sendo que esses dois últimos grupos estão em posições muito próximas. Abaixo, afastado dos demais, estão os meninos pretos.

Assim, a estrutura de desigualdades educacionais por grupo racial é marcada por uma diferença sensível entre a posição das pessoas autoclassificadas como pardas e como pretas. Em todas as faixas de NSE, no interior dos grupos de gênero, tanto as meninas pardas têm desempenho mais próximo das meninas brancas do que das meninas pretas, como os meninos pardos têm desempenho mais próximo dos meninos brancos do que dos meninos pretos. Ou seja, os mecanismos geradores das desigualdades educacionais geram desvantagens muito maiores para as pessoas pretas do que para as pardas, mais intensamente ainda para os meninos pretos.

O grau em que o aumento do NSE se associa ao aumento do nível de aprendizagem varia em cada grupo, confirmando resultados de Soares e Alves (2003). As meninas brancas têm o maior aumento de nível de aprendizagem entre o NSE 1 e o NSE 5; em seguida vêm as meninas pardas, os meninos brancos, as meninas pretas e os meninos pardos. A menor variação é dos meninos pretos, para quem o aumento do NSE tem menor impacto sobre o aumento de seu nível de aprendizagem.

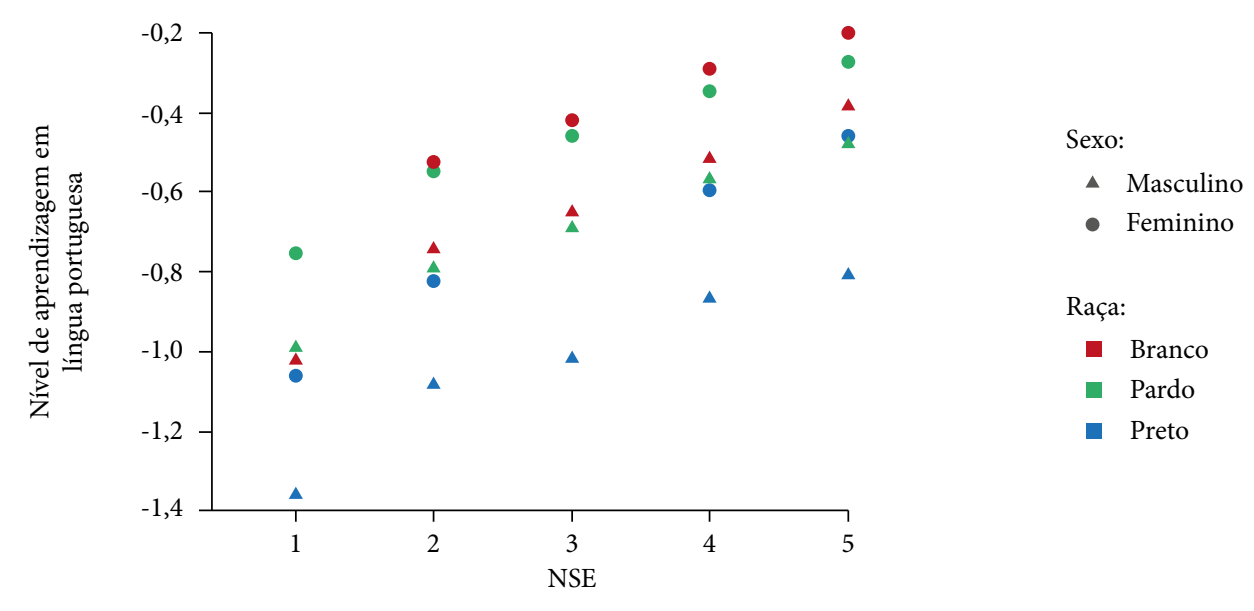

Figura 5. Nível de aprendizagem em Língua Portuguesa de grupos de estudantes paulistanos por NSE, raça e gênero. 


\section{Grupos de Alunos em Agrupamentos de Distritos}

Analisamos também essa estrutura de desigualdades nos quatro agrupamentos de distritos, resultados que estão disposto na Figura 6. Por causa do fracionamento dos grupos de estudantes em agrupamento de distritos, as amostras são menores e, portanto, mais sujeitas a flutuações aleatórias. Como medida de cautela, só consideramos grupos com pelo menos 100 indivíduos.

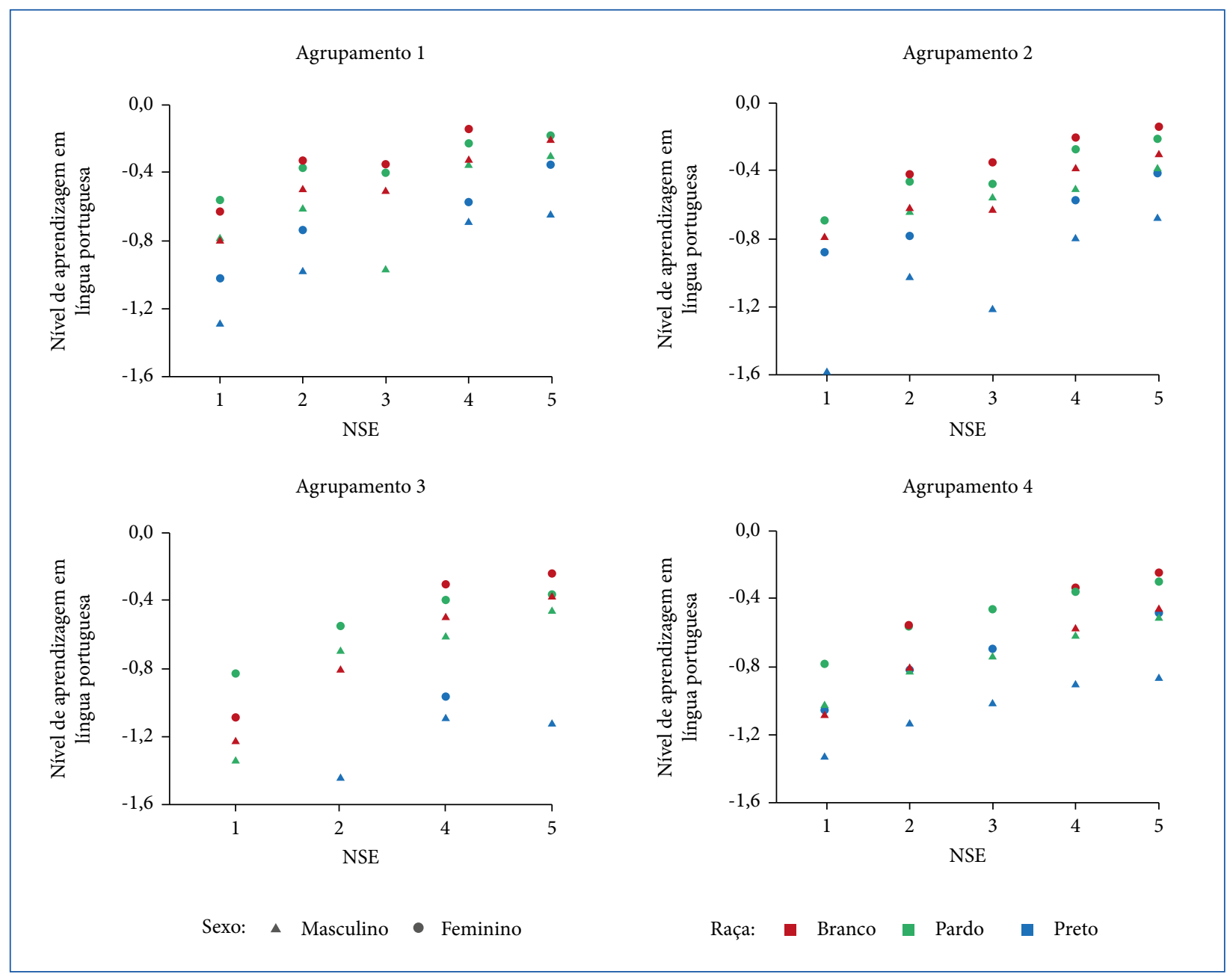

Figura 6. Nível de aprendizagem em Língua Portuguesa de grupos de estudantes paulistanos por NSE, raça e gênero em agrupamento de distritos.

\section{Agrupamento 1: Aprendizagens Maiores e Desigualdades Maiores}

Nesse agrupamento, de modo geral, todos os grupos de estudantes têm os níveis mais altos de aprendizagem da cidade. No que diz respeito às desigualdades, pode-se notar que, em todos os grupos de NSE, o sistema de posições relativas dos grupos formados por raça e gênero é o mesmo que o da cidade (meninas brancas, meninas pardas, meninos brancos, meninos pardos, meninas pretas, meninos pretos). Entretanto, o padrão de três feixes encontrado na cidade não é tão nítido aqui: nesses distritos, os meninos brancos e os meninos pardos estão mais próximos das meninas brancas e pardas, que se mantêm nas posições mais altas. As meninas pretas estão mais afastadas dos meninos pardos do que se vê na cidade. Os meninos pretos são o grupo com a menor variação no nível de aprendizagem de sua fração com NSE 5 em relação à de NSE 1. Essa variação é maior entre as meninas brancas. 
Em síntese, esse é o agrupamento de distritos mais branco, onde há maior segregação residencial da população mais rica e onde os alunos das escolas públicas têm o maior NSE médio. É também o agrupamento no qual as escolas públicas asseguram aprendizagem maior, inclusive para os meninos pretos. Entretanto, é também aquele em que há desigualdades internas perceptíveis, fortemente marcadas pelo sistema de classificação racial, em prejuízo, sobretudo, das meninas pretas e, mais ainda, dos meninos pretos.

\section{Agrupamento 2: Aprendizagens Maiores e Desigualdades Menores}

As aprendizagens dos estudantes desse agrupamento também são maiores que o que se vê na cidade. No que diz respeito às desigualdades internas, pode-se notar que, em todos os grupos de NSE, o sistema de posições relativas dos grupos formados por raça e gênero é o mesmo da cidade. Também aqui o padrão de três feixes não é tão nítido. Assim como no agrupamento 1, os meninos brancos e os pardos estão mais próximos das meninas brancas e pardas, que se mantêm nas posições mais altas. Aqui, de modo geral, as meninas pretas têm níveis de aprendizagem mais próximos aos dos meninos pardos do que nos agrupamentos 1 e 3. Afastados, em posição de desvantagem, estão os meninos pretos, que, novamente, são o grupo com a menor variação no nível de aprendizagem de sua fração com NSE 5 em relação à de NSE 1. Essa variação é maior entre as meninas brancas.

Portanto, nesse agrupamento de distritos que reúnem grupos médios da cidade e que possuem estudantes com NSE médio, agrupamento esse caracterizado por níveis de aprendizagem mais altos e menores desigualdades, também persiste a desvantagem dos meninos pretos. Entretanto, nele, as meninas pretas têm, no geral, níveis de aprendizagem mais altos, relativamente, afastando-se dos meninos pretos e se aproximando mais dos meninos pardos e brancos.

\section{Agrupamento 3: Aprendizagens Menores e Desigualdades Maiores}

Nesse agrupamento, que concentra estudantes de NSE baixo, as aprendizagens são, no geral, mais baixas do que as verificadas no conjunto da cidade. No que diz respeito às desigualdades internas, pode-se notar que, em todos os grupos de NSE, o sistema de posições relativas dos grupos formados por raça e gênero é o mesmo do encontrado no conjunto da cidade. Também aqui o padrão de três feixes encontrado na cidade não é tão nítido. Chama a atenção a baixa representação de estudantes pretos, sobretudo meninas pretas, só permitindo a construção de amostra para o NSE 4. Elas estão distantes dos meninos pardos de mesmo NSE, em padrão semelhante ao do agrupamento 1. Também aqui os meninos pretos têm desempenho mais baixo e são o grupo com a menor variação no nível de aprendizagem de sua fração com NSE 5 em relação à de NSE 1. Igualmente, essa variação é maior entre as meninas brancas.

Ou seja, também nesse outro agrupamento, caracterizado por forte segregação escolar e desigualdades educacionais mais altas, as desigualdades educacionais raciais são acentuadas, penalizando mais intensamente as meninas pretas e, ainda mais, os meninos pretos.

\section{Agrupamento 4: Aprendizagens Menores e Desigualdades Menores}

As aprendizagens nesse grupo são, no geral, mais baixas do que as verificadas no conjunto da cidade. No que diz respeito às desigualdades, pode-se notar que, em todos os grupos de NSE, o sistema de posições relativas dos grupos formados por raça e gênero é quase o mesmo do encontrado no conjunto da cidade. Esse agrupamento, também o mais populoso, é o único no qual o padrão de três feixes verificado na cidade é nítido. Nele, as meninas pretas não só estão mais próximas dos meninos pardos, como, à exceção de 
sua fração de menor NSE, têm nível de aprendizagem maior do que eles. Novamente, os meninos pretos são o grupo com a menor variação no nível de aprendizagem de sua fração com NSE 5 em relação à de NSE 1. Essa variação é maior entre as meninas brancas.

No agrupamento de estudantes de menor NSE, mais negro e também com aprendizagens mais baixas e desigualdades menores, as meninas brancas e pardas de NSE 4 e 5 estão isoladas dos demais grupos, com desempenho mais alto, embora em nível mais baixo que o verificado na cidade. Nesse agrupamento, as meninas pretas estão não apenas próximas dos meninos pardos, como os superam em quase todas as faixas de NSE. Novamente, a desvantagem dos meninos pretos é evidente.

\section{Discussão}

Os padrões que descrevemos confirmam, ainda que parcialmente, os resultados de outros trabalhos. Assim como Torres et al (2008), Ernica e Batista (2012) e Perosa et al. (2015), observamos que as desvantagens educacionais estão concentradas nos distritos mais periféricos e/ou com maior segregação social de pobreza (agrupamentos 3 e 4). Do mesmo modo, nossos dados também corroboram a conclusão de que os níveis mais altos de aprendizagem, para todos os grupos socioesconômicos, se dão nas escolas dos distritos habitados pelos grupos médios e mais ricos (agrupamentos 1 e 2). No entanto, fazemos duas ressalvas: a primeira é que os distritos habitados pela população mais rica, que têm os estudantes de maior NSE e mais brancos, são internamente mais desiguais e sua desigualdade tem forte viés racial, prejudicando meninas pretas e, sobretudo, meninos pretos; a segunda é que as oportunidades educacionais melhores e mais equitativas estão localizadas nos bairros habitados majoritariamente pelas camadas médias.

Ao analisarmos grupos de estudantes definidos por NSE, raça e gênero, identificamos uma estrutura de desigualdades estável. Nela, em todos os grupos de NSE, as meninas brancas e pardas são os grupos com os maiores níveis de aprendizagem, sempre próximos, embora com vantagem para as brancas. Os meninos brancos e pardos vêm a seguir, também próximos e também com vantagem para os brancos. As meninas pretas vêm logo após. Por fim, estão os meninos pretos, grupo mais penalizado, com as piores oportunidades educacionais e para quem o aumento do NSE está associado ao menor aumento do nível de aprendizagem.

Nossos resultados também confirmam parcialmente outro padrão encontrado na literatura: frações de um mesmo grupo social, quando estudam em regiões diferentes da cidade, têm desempenho distinto. De fato, as frações dos grupos de alunos que estudam nas regiões de maiores oportunidades educacionais (agrupamentos 1 e 2) têm nível de aprendizagem mais alto; por sua vez, a aprendizagem das frações que estudam nas regiões de menores oportunidades (agrupamentos 3 e 4 ) é mais baixa.

No entanto, devemos nuançar essa tese, pois a variação nas oportunidades educacionais produzidas pela estrutura socioespacial não é homogênea entre os grupos definidos por NSE, raça e gênero. Essa variação é bastante evidente no caso das meninas pretas, grupo cujas aprendizagem e posição no sistema de desigualdades variam conforme o padrão das desigualdades dos distritos: elas estão mais distantes dos meninos pardos nos distritos mais desiguais e mais próximas deles nos distritos mais equitativos, chegando a ultrapassá-los no agrupamento 4 .

As explicações disponíveis na literatura sobre desigualdades educacionais nas metrópoles se apoiam em uma premissa teórica e apontam dois grandes conjuntos de mecanismos produtores. A premissa é que as desigualdades socioespaciais são uma estrutura relativamente autônoma e com consequências sobre a distribuição desigual de oportunidades educacionais, alterando os resultados que seriam devidos ao NSE dos estudantes. Os mecanismos são: i) a transposição dos padrões de segregação residencial para 
o sistema escolar, no qual, transformados, assumem a forma de segregação escolar; e ii) a distribuição desigual e regressiva, ao longo da cidade e dos sistemas de ensino, de recursos de políticas sociais e educacionais.

Nossos resultados empíricos corroboram essa premissa e esses mecanismos. Entretanto, mostram que eles não são suficientes para explicar os padrões de desigualdades que descrevemos. Não é nosso objetivo propor explicações, o que requer novas pesquisas. Não obstante, podemos sustentar uma premissa teórica geral e formular uma hipótese.

A premissa é que, se a estrutura de posições sociais, medida pelo NSE, é um forte preditor de resultados educacionais, há outras estruturas relativamente autônomas que, ao se relacionarem com a de posições sociais, geram padrões específicos de desigualdades. A estrutura de desigualdades socioespaciais é uma delas, como também o são as estruturas racial e de gênero.

Nossa hipótese, a partir do caso paulistano, é que as vantagens escolares das meninas brancas e pardas, sobretudo as de maior NSE, são persistentes entre as regiões da cidade porque esses grupos reuniriam os atributos mais valorizados e rentáveis no espaço escolar, permitindo-lhes receber as melhores oportunidades educacionais. Os meninos brancos e pardos vêm a seguir. As meninas pretas só se beneficiariam de melhores oportunidades educacionais em distritos mais equitativos, qualquer que seja o seu nível de aprendizagem. Nesses contextos, para elas, os efeitos negativos da discriminação racial seriam relativamente enfraquecidos, abrindo brechas para que características femininas valorizadas e rentáveis no espaço escolar pudessem operar como trunfos, assegurando-lhes melhores oportunidades educacionais e permitindo-lhes, em certas condições, nível de aprendizagem superior ao dos meninos pardos. O abrandamento relativo da restrição das oportunidades educacionais pela discriminação racial não ocorreria para os meninos pretos, no entanto, que receberiam os piores juízos e as piores oportunidades educacionais em qualquer contexto, inclusive nos distritos mais equitativos. Assim, se essa desvantagem é particularmente aguda e trágica para os meninos pretos de menor NSE, os quais reúnem os atributos associados às piores oportunidades educacionais em qualquer contexto, ela é forte ao ponto de não ceder mesmo diante de atributos associados ao NSE, que são trunfos potentes no espaço escolar - mas para outros grupos.

\section{Contribuição dos Autores}

Problematização e Conceitualização: Ernica M, Rodrigues EC; Metodologia: Ernica M, Rodrigues EC; Análise: Ernica M, Rodrigues EC; Redação: Ernica M, Rodrigues EC

\section{Notas}

1. Segundo o IBGE (2016, p. 22), "um arranjo populacional é o agrupamento de dois ou mais municípios onde há uma forte integração populacional devido aos movimentos pendulares para trabalho ou estudo ou devido à contiguidade entre as manchas urbanizadas principais".

2. Ver Ribeiro e Vovio (2017) para uma discussão mais pormenorizada desse debate

3. Como tamanho mínimo dos grupos para a construção dos indicadores, 100 pessoas foram consideradas para o cálculo da qualidade da aprendizagem e 20 pessoas para cálculo das desigualdades. Não foi possível contar com todos os 96 distritos para os dois anos escolares. Para resultados do 50 ano, só puderam ser analisados 95 distritos, ficando de fora o Jardim Paulista, uma vez que a rede pública nele presente não oferece o primeiro segmento do Ensino Fundamental. 
4. A Prova Brasil é uma avaliação censitária de larga escala, realizada bienalmente desde 2005. Ela mede resultados de aprendizagens de estudantes das séries finais do primeiro e do segundo segmentos do Ensino Fundamental em duas disciplinas: Língua Portuguesa, com foco em leitura, e Matemática, com foco em resolução de problemas. Ao responderem a prova, os estudantes respondem também um questionário socioeconômico. Disponível em: http://portal.mec.gov.br/ prova-brasil

5. A Kulbach-Leibler é uma medida descritiva da divergência entre duas distribuições de probabilidade. Diferentemente das comparações de medidas-resumo - como as médias -, a Kulbach-Leibler é calculada diretamente das distribuições inteiras, baseando-se nas razões entre as densidades em cada ponto das distribuições. Para uma exposição sistemática, ver Kullback (1997).

6. O modelo teórico apoia-se no debate sobre justiça distributiva, que se desenvolve desde os anos 1950, e procura definir quais desigualdades ferem as ideias de justiça (KYMLICKA, 1999). A definição de desigualdade adotada tem grande afinidade com a proposta por John E. Roemer (1998), para quem devem ser consideradas injustas as desigualdades de resultados verificadas entre grupos da população definidos por atributos que sejam explicativos desses resultados e pelos quais os indivíduos não possam ser responsabilizados. Tal autor chama esses grupos de tipos: "a type comprises the set of individuals with the same circunstances, where circunstances are those aspects of one's environement (including, perhaps, one's biological characteristics) that are beyond one's control, but that also influence the outcomes of interest" (ROEMER; TRANNOY, 2016, p. 1293).

7. O Programme for International Student Assessment (PISA) é um estudo comparativo internacional realizado pela Organização para a Cooperação e Desenvolvimento Econômico (OCDE). O PISA mede as competências da população de 15 anos em leitura, matemática e ciências. O Brasil participa do PISA desde sua primeira edição, em 2000.

8. O cálculo do NSE partiu da metodologia desenvolvida por Alves et al. (2014). Inicialmente, calculamos, para cada estudantes brasileiro, um valor do NSE. Esses valores foram padronizados, assegurando-se média $=0$, desvio padrão $=$ 1 e amplitude de dados entre -3 e +3 . Para calcular os cinco grupos de NSE do país, os estudantes foram agrupados em quintis. Utilizamos os cinco grupos assim obtidos na análise do município de São Paulo.

9. O questionário socioeconômico da Prova Brasil usa o mesmo critério do IBGE para investigar cor ou raça dos indivíduos, os quais se autoclassificam em um sistema de cinco categorias: brancos, amarelos, indígenas, pardos e pretos. Juntos, pretos e pardos formam a categoria negros. As pesquisas sobre desigualdades de aprendizagem (ALVES et al., 2016) revelam desigualdades sensíveis entre pardos e pretos, sendo esses últimos o grupo em maior desvantagem. Por isso, trabalhamos separadamente com os grupos de pretos e pardos e, na produção dos indicadores de desigualdades entre grupos raciais, comparamos os grupos em posições extremas: brancos e pretos.

10. Utilizamos a categoria gênero porque, ao utilizarmos a variável sexo, o objeto teórico que nos importa é a relação da estrutura de gênero com as desigualdades educacionais. Isto é: o papel na definição de desigualdades educacionais que é exercido por essa estrutura hierarquizada de categorias forjada a partir da percepção dos corpos sexuados e que define identidades, usos dos corpos, práticas, que se enraíza em instituições e se extravasa para todo o mundo, recobrindo tanto aromas e cores, quanto as aprendizagens e as trajetórias escolares.

11. Água Rasa; Barra Funda; Bela Vista; Brás; Butantã; Cambuci; Carrão; Casa Verde; Jaguara; Lapa; Mandaqui; Moema; Mooca; Penha; Perdizes; Pinheiros; República; São Lucas; Saúde; Santa Cecília; Santana; Santo Amaro; Tatuapé; Tucuruvi; Vila Formosa; Vila Guilherme; Vila Mariana.

12. Calculado pela Fundação Seade, o IPVS (Índice Paulista de Vulnerabilidade Social) é um indicador sintético, calculado para cada setor censitário do estado, e que mede a exposição das famílias à pobreza. Acessar http://www.seade.gov.br/ ipvs/ para mais informações.

13. O NSE médio dos agrupamentos pode ser interpretado como a distância, em unidades de desvio-padrão, em relação à média nacional. Assim, o NSE médio do agrupamento 1 é de 0,48 desvios-padrão acima da média nacional. O mesmo raciocínio se aplica aos demais agrupamentos.

14. A Prova Brasil só é aplicada nas escolas públicas.

15. Aricanduva; Campo Grande; Cangaiba; Cursino; Freguesia do Ó; Ipiranga; Itaim Bibi; São Mateus; Sacomã; Vila Matilde; Vila Medeiros; Vila Prudente.

16. Alto de Pinheiros; Belém; Consolação; Jaguaré; Liberdade; Morumbi; Pari; Sé; Socorro; Vila Leopoldina.

17. Anhanguera; Artur Alvim; Bom Retiro; Brasilândia; Cachoeirinha; Campo Belo; Campo Limpo; Capão Redondo; Cidade Ademar; Cidade Dutra; Cidade Líder; Cidade Tiradentes; Ermelino Matarazzo; Grajaú; Guaianases; Iguatemi; Itaim Paulista; Itaquera; Jaçanã; Jabaquara; Jaraguá; Jardim Ângela; Jardim Helena; Jardim São Luís; José Bonifácio; Lajeado; Limão; Marsilac; Parelheiros; Parque do Carmo; Pedreira; Perus; Pirituba; Ponte Rasa; Raposo Tavares; Rio Pequeno; São Domingos; São Miguel; São Rafael; Sapopemba; Tremembé; Vila Andrade; Vila Curuçá; Vila Jacuí; Vila Maria; Vila Sônia. 


\section{Referências}

ALVES, L. et al. Seleção velada em escolas públicas: Práticas, processos e princípios geradores. Educação e Pesquisa, v. 41, p. 137-152, 2015a. https://doi.org/10.1590/S1517-97022015011488

ALVES, L. et al. Remoção de professores e desigualdades em territórios vulneráveis. Cadernos Cenpec, v. 4, p. 122-145, 2015b. http://doi.org/10.18676/cadernoscenpec.v4i2.292

ALVES, M. T. G.; SOARES, J. F.; XAVIER, F. P. Índice socioeconômico das escolas de educação básica brasileiras. Ensaio: Avaliação e Políticas Públicas em Educação, Rio de Janeiro, v. 22, n. 84, p. 671-703, set., 2014. https://doi.org/10.1590/S0104-40362014000300005

ALVES, M. T. G.; SOARES, J. F.; XAVIER, F. P. Desigualdades educacionais no ensino fundamental de 2005 a 2013: hiato entre grupos sociais. Revista Brasileira de Sociologia, v. 4, n. 7, p. 49-81, jan.-jun. 2016

BAUDELOT, C.; ESTABLET, R. Allez les filles! Paris: Ed. du Seuil, 1992.

BECKER, H. The career of the Chicago public schoolteacher. American Journal of Sociology, v. 57, n. 5, p. 470-477, mar. 1952.

BEN AYED, C. (coord.) École ségrégative, école reproductive. Actes de la Recherche en Sciences Sociales, n. 180, 2009. https://doi.org/10.3917/arss.180.0004

BEN AYED, C. La mixité sociale à L’école: Tensions, enjeux, perspectives. Paris: Armand Colin, 2015.

CARVALHO, M. P. O fracasso escolar de meninos e meninas: Articulações entre gênero e cor/raça. Cadernos Pagu, n. 22, p. 247-290, 2004. https://doi.org/10.1590/S0104-83332004000100010

CARVALHO, M. P. Quem é negro, quem é branco: Desempenho escolar e classificação racial de alunos. Revista Brasileira de Educação, n. 28, p. 77-96, jan.-abr. 2005. https://doi.org/10.1590/S1413-24782005000100007

CARVALHO, M. P.; SENKEVICS, A. S.; LOGES, T. A.. O sucesso escolar de meninas de camadas populares: Qual o papel da socialização familiar? Educação e Pesquisa, v. 40, n. 3, p. 717-734. 2014. https://doi. org/10.1590/s1517-97022014091637

COSTA, M.; KOSLINSKI, M. C. Quase-mercado oculto: Disputa por escolas "comuns" no Rio de Janeiro. Cadernos de Pesquisa, São Paulo, v. 41, n. 142, p. 246-266, jan.-abr. 2011. https://doi.org/10.1590/ S0100-15742011000100013

COSTA, M.; KOSLINSKI, M. C. Escolha, estratégia e competição por escolas públicas. Pro-Posições, Campinas, v. 23, n. 2, p. 195-213, maio-ago. 2012. https://doi.org/10.1590/S0103-73072012000200013

DE SAINT-MARTIN, M. Uma "boa" educação. Educação \& Sociedade, Campinas, ano XX, n. 66, p. 104122, abr. 1999.

ERNICA, M. Desigualdades educacionais no espaço urbano: O caso de Teresina. Revista Brasileira de Educação, v. 18, p. 523, 2013. http://doi.org/10.1590/S1413-2478201300030000211

ERNICA, M.; BATISTA, A. A. G.. A escola, a metrópole e a vizinhança vulnerável. Cadernos de Pesquisa, v. 42, p. 640-666, 2012. http://doi.org/10.1590/S0100-15742012000200016 
FRANÇA, D. S. N. Segregação racial em São Paulo: residências, redes pessoais e trajetórias urbanas de negros e brancos no século XXI. 2017. Tese (Doutorado em Filosofia) - Faculdade de Filosofia, Letras e Ciências Humanas, Universidade de São Paulo, São Paulo, 2017.

HASENBALG, C. A.; SILVA, N. V. Raça e oportunidades educacionais no Brasil. Cadernos de pesquisa, São Paulo, n. 73, p. 5-12, mai. 1990.

IBGE [INSTITUTO BRASILEIRO DE GEOGRAFIA E ESTATÍSTICA]. Regiões de Influência das Cidades - 2007. Rio de Janeiro: IBGE, 2008.

IBGE [INSTITUTO BRASILEIRO DE GEOGRAFIA E ESTATÍSTICA]. Arranjos populacionais e concentração urbana no Brasil. Rio de Janeiro: IBGE, 2016.

KYMLICKA, W. Les théories de la justice - Une introduction. Paris: La Découverte, 2003.

KOSLINSKI, M. C.; ALVES, F. Novos olhares para as desigualdades de oportunidades educacionais: a segregação residencial e a relação favela-asfalto no contexto carioca. Educação \& Sociedade, Campinas, v. 33, n. 120, p. 783-803, 2012. https://doi.org10.1590/S0101-73302012000300009

KOSLINSKI, M. C.; ALVES, F.; LANGE, W. J.. Desigualdades educacionais em contextos urbanos: Um estudo da geografia de oportunidades educacionais na cidade do Rio de Janeiro. Educação \& Sociedade, Campinas, v. 34, n. 125, p. 1175-1202, dec. 2013. https://doi.org/10.1590/S0101-73302013000400009

KULLBACK, S. Information theory and statistics. North Chelmsford: Courrier Corporation, 1997.

MERLE, P. La démocratisation de l’enseignement. Paris: La Découverte, 2017.

PADILHA, F. et al. As regularidades e exceções no desempenho no IDEB nos municípios. Estudos em Avaliação Educional, São Paulo, v. 23, n. 51, p. 58-81, jan./abr. 2012. http://doi.org/10.18222/eae235120121948

PEROSA, G. S.; LEBARON, F.; LEITE, C. K. S. O espaço das desigualdades educativas no município de São Paulo. Pro-Posições, Campinas, v. 26, n. 2, p. 99-118, maio-ago. 2015. https://doi.org/10.1590/0103-7307201507705

REARDON, S. F et al. Gender Achievement Gaps in U.S. School Districts. CEPA Working Paper n..18-13. Stanford, 2018.

REARDON, S. F. et al. Is Separate Still Unequal? New Evidence on School Segregation and Racial Academic Achievement Gaps. CEPA Working Paper n. 19-06. Stanford, 2019.

REARDON, S. F.; OWNENS, A. 60 years after Brown: Trends and consequences of school segregation. Annual Review of Sociology, v. 40, n. 9, p. 1-9, May 2014. https://doi.org/10.1146/annurev-soc-071913-043152

RIBEIRO, L. C. Q.; KOSLINSKI, M. Efeito metrópole e acesso às oportunidades educacionais. Revista Eure, v XXXV, n. 106, p. 101-129, 2009. http://doi.org/10.4067/S0250-71612009000300006

RIBEIRO, V. M.; VOVIO, C. L. Desigualdade escolar e vulnerabilidade social no território. Educar em Revista, Curitiba, n. esp. 2, p. 71-87, set. 2017. https://doi.org/10.1590/0104-4060.51372

ROEMER, J. E. Equality of opportunity. Cambridge: Harvard University Press, 1998.

ROEMER, J. E.; TRANNOY, A. Equality of opportunity: Theory and measurement. Journal of Economic Literature, v. 54, n. 4, p. 1288-1332, 2016. n. p. 104-122, . 19 
SCHAUB, J. F. Pour une histoire politique de la race. Paris: Seuil, 2015.

SOARES, J. F.; ALVES, M. T. G. Desigualdades raciais no sistema brasileiro de educação básica. Educação e Pesquisa, São Paulo, v. 29, n. 1, p. 147-165, jan.-jun. 2003. https://doi.org/10.1590/S1517-97022003000100011

SOARES, J. F.; DELGADO, V. M. S. Medida das desigualdades de aprendizado entre estudantes de ensino fundamental. Estudos em Avaliação Educacional, v. 27, p. 754-780, 2016. http://doi.org/10.18222/eae. v27i66.4101

SOARES, J. F.; RODRIGUES, E. C.; ERNICA, M. IDeA - Indicador de desigualdades e aprendizagens. Nota técnica. São Paulo: Fundação Tide Setubal, 2019.

TORRES, H. G. Medindo a segregação. In: MARQUES, E.; TORRES, H. G. São Paulo: Segregação, pobreza e desigualdades sociais. São Paulo: Senac, 2004.

TORRES, H. G. et al. Educação na periferia de São Paulo: Ou como pensar as desigualdades educacionais. In: RIBEIRO, L. C. Q.; KAZTMAN, R. (orgs.). A Cidade contra a Escola? Segregação urbana e desigualdades educacionais em grandes cidades da América Latina. Rio de Janeiro: Letra Capital/Montevidéu: Ippes, 2008. p. 59-90.

VAN ZANTEN, A. La sociologie de l'éducation en milieu urbain: Discours politiques, pratiques de terrain et production scientifique, 1960-1990. Revue française de pédagogie, v. 95, p. 115-142, 1991.

VAN ZANTEN, A. L'école de la péripherie: Scolarité et ségrégation em banlieue. Paris: PUF, 2001.

WACQUANT, L. Os condenados da cidade. Rio de Janeiro: Revan/FASE, 2001.

WILSON, W. J. The new urban poverty and the problem of race. The Tanner Lectures on Human Values. University of Michigan, 1993.

\section{Sobre os Autores}

MaURicio Ernica é bacharel em Ciências Sociais (USP), Mestre em Antropologia Social (Unicamp) e Doutor em Linguística Aplicada e Estudos da Linguagem (PUC-SP), tendo realizado parte de sua formação doutoral na Universidade de Genebra. Atuou por 17 anos em instituições do terceiro setor. Desde 2013, é professor da Faculdade de Educação da Unicamp. Seus interesses de pesquisa são educação, cultura e desigualdades.

Erica Castilho Rodrigues é bacharel, Mestre e Doutora em Estatística pela Universidade Federal de Minas Gerais (UFMG). Desde 2012, é professora do Departamento de Estatística da Universidade Federal de OuroPreto. Seus interesses de pesquisa são estatística espacial, teoria da resposta ao item, avaliação educacional e desigualdades educacionais.

Recebido: 10 set. 2019 Aceito: 03 abr. 2020 